\title{
CHEMICAL MIMICRY AS AN INTEGRATING MECHANISM FOR THREE TERMITOPHILES ASSOCIATED WITH RETICULITERMES VIRGINICUS (BANKS) 1,2
}

\author{
By Ralph W. Howard, ${ }^{3,4}$ C. A. McDaniel, 5 \\ AND GARY J. BLOMQUIST ${ }^{6}$ \\ INTRODUCTION
}

The mechanisms by which termitophiles integrate themselves into the social life of termite colonies have long intrigued entomologists (Kistner, 1979). Various authors have suggested that plausible integration mechanisms might include the using of "appeasement chemicals" (Wilson, 1971), passing as morphological mimics (Kistner, 1968), or engaging in behavioral mimicry (Kistner, 1979). We recently reported (Howard et al., 1980a) that the host-specific, highly integrated termitophile Trichopsenius frosti Seevers associated with Reticulitermes flavipes (Kollar) possesses the same complex mixture of cuticular hydrocarbons as its termite host. We suggested that this was an example of chemical mimicry which functioned to integrate this beetle into the termite society.

Reticulitermes virginicus (Banks) is sympatric with $R$. flavipes throughout much of its range and, as predicted (Howard et al., 1978; Blomquist et al., 1979), the two species possess distinctly different cuticular hydrocarbons which function as species recognition cues (Howard et al., 1982). They also have different termitophilous cohorts. Thus, $T$. frost $i$ is associated only with $R$. flavipes whereas T. depressus Le Conte, Xenistusa hexagonalis Seevers (both Staphylinidae: Trichopseniinae), and Philotermes how'ardi Kistner and Gut (Staphylinidae: Aleocharinae) are associated only with $R$. virginicus. We now report that the three $R$. virginicus staphylinids also appear to use chemical mimicry as an integrating mechanism; i.e.,

'Manuscript received by' the editor June 3, 1982.

2Isoptera: Rhinotermitidae.

${ }^{3}$ Forestry Sciences Laboratory, Southern Forest Experiment Station, P. O. Bo.x 2008 GMF, Gulfport, MS 39503.

${ }^{4}$ Author to whom correspondence should be addressed.

${ }^{5}$ National Monitoring and Residue Analysis Laboratory, USDA Animal and Plant

Health Inspection Service, P. O. Box 3209. Gulfport, MS 39503.

'Department of Biochemistry, University' of Nevada-Reno, Reno, NV 89557 
they have the same complex mixture of cuticular hydrocarbons as their host termite. In addition, we report that at least one of these beetles ( $X$. hexagonalis) biosynthesizes its hydrocarbons.

\section{Methods ANd Materials}

Portions of several colonies of $R$. virginicus were collected in 1979 from pine logs in Harrison, Jackson, and Stone Counties, Mississippi. The beetles were separated from the termites, counted by species, and stored at $-20^{\circ} \mathrm{C}$ until used. A total of 230 beetles was collected: 10 P. howardi, $140 \mathrm{~T}$. depressus, and $80 \mathrm{X}$. hexagonalis. Cuticular hydrocarbons from pooled samples (by species) were isolated and separated as previously described (Howard et al., 1978). Hydrocarbons were characterized by gas-liquid chromatography (GC) retention times and by electron impact (EI) and chemical ionization (CI) mass spectrometry (Howard et al., 1980b; Jackson and Blomquist, 1976). Double bond stereochemistries were determined by comparison with standards using argentation thin-layer chromatography ( $\left.\mathrm{AgNO}_{3}-\mathrm{TLC}\right)$ (Kates, 1972).

In vitro biosynthesis experiments were conducted as previously described (Howard et al., 1980a) using $60 \mathrm{X}$. hexagonalis collected from a single colony of $R$. virginicus in September 1979.

Radioactivity was assayed by liquid scintillation counting for 10 minutes at about 85 percent counting efficiency. All counting was done with a standard deviation of less than 5 percent. A portion of the isolated hydrocarbons was assayed for total radioactivity. The remainder of the material was separated by $\mathrm{AgNO}_{3}-\mathrm{TLC}$ into saturated, monounsaturated, and diunsaturated components, which then were assayed for radioactivity.

\section{RESULTS}

The retention times of all peaks present in the GC profile of cuticular hydrocarbons from $R$. virginicus (Fig. 1) match those from the GC profile of the cuticular hydrocarbons of $P$. howardi (Fig. 2), $T$. depressus (Fig. 3), and X. hexagonalis (Fig. 4). Confirmation of the chemical identity for each of the hydrocarbon components in most of the GC peaks was obtained by EI and CI mass spectrometry (MS). In every instance, the GC-MS retention times and mass spectra of the beetle hydrocarbon components were identical to those 
previously obtained from $R$. virginicus cuticular hydrocarbons (Howard et al., 1982). Likewise, concurrently obtained $\mathrm{AgNO}_{3}-\mathrm{TLC}$ retention values $\left(\mathrm{R}_{\mathrm{f}}\right)$ were identical for all beetle derived alkenes and $R$. virginicus alkenes. Components which were identified include n-alkanes, 2-, 3-, 11-, 13-, and 15-methylalkanes, 11,15-dimethylalkanes, Z-9-alkenes, Z,Z-7,9-dienes, and E/Z-6,9dienes ranging in carbon number from $\mathrm{C}_{21}$ to $\mathrm{C}_{40}$ (Table 1). Double bond location and stereochemistries of the beetle derived alkenes were inferred solely from GC and GC-MS retention time data, and $\mathrm{AgNO}_{3}-\mathrm{TLC} \mathrm{R}_{\mathrm{f}}$ data, since insufficient sample was available for infrared analysis and methoxymercuration-demercuration (Blomquist et al., 1980). Early eluting components not identified by a number in Figures 1 to 4 are unidentified, but have retention times consistent with a homologous series of $n$-alkanes.

The relative abundance of individual hydrocarbon components varied from species-to-species, but no more so than that of their termite host, whose percent composition varies considerably by caste (Howard et al., 1982).

The in vitro radioisotope incorporation experiment was conducted with $X$. hexagonalis to determine if this species can biosynthesize its cuticular hydrocarbons de novo. Howard (1978) reported that this species engages in frequent allogrooming with its termite host, with the resulting possibility of acquiring host hydrocarbons by mechanical transfer rather than by de novo biosynthesis. A combination of these two alternatives is also possible. After 2 hours of incubating beetle cuticular tissues with $10 \mu \mathrm{Ci}$ of $\left[1-{ }^{14} \mathrm{C}\right]$-acetate, $19.6 \pm 8.8$ pmole (mean $\pm \mathrm{SD}$ ) of $\left[1-{ }^{14} \mathrm{C}\right]$-acetate was incorporated into hydrocarbon. About $87.8 \pm 5.3$ percent of the radioactivity was in the alkane fraction, $10.2 \pm 4.0$ percent was in the alkene fraction, and $1.9 \pm 1.3$ percent was in the alkadiene fraction. This closely approximates the distribution of alkanes and olefins in $X$. hexagonalis, suggesting that this species can de novo biosynthesize its cuticular hydrocarbons. In vitro biosynthesis experiments were not conducted with $T$. depressus and $P$. howardi because we were unable to collect enough beetles simultaneously.

\section{Discussion}

The striking mimicry of hydrocarbon components observed among these three beetles (representing two subfamilies) and their 


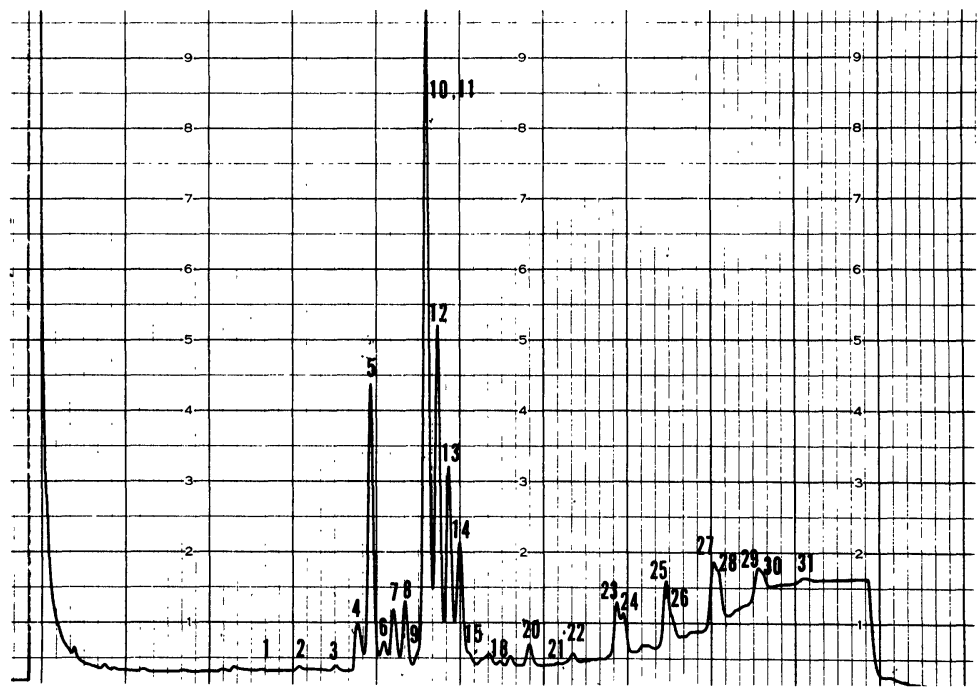

Fig. 1. GC trace of total cuticular hydrocarbons of Reticulitermes virginicus. GC conditions: $1.83 \mathrm{~m} \times 3 \mathrm{~mm}$ i.d. Stainless steel column packed with 3 percent $(w / w)$ $\mathrm{SP}-2100$ on $100 / 120$ mesh Supelcoport; temperature programmed from $150^{\circ}$ to $325^{\circ} \mathrm{C}$ at $5^{\circ} \mathrm{C} / \mathrm{min}$.

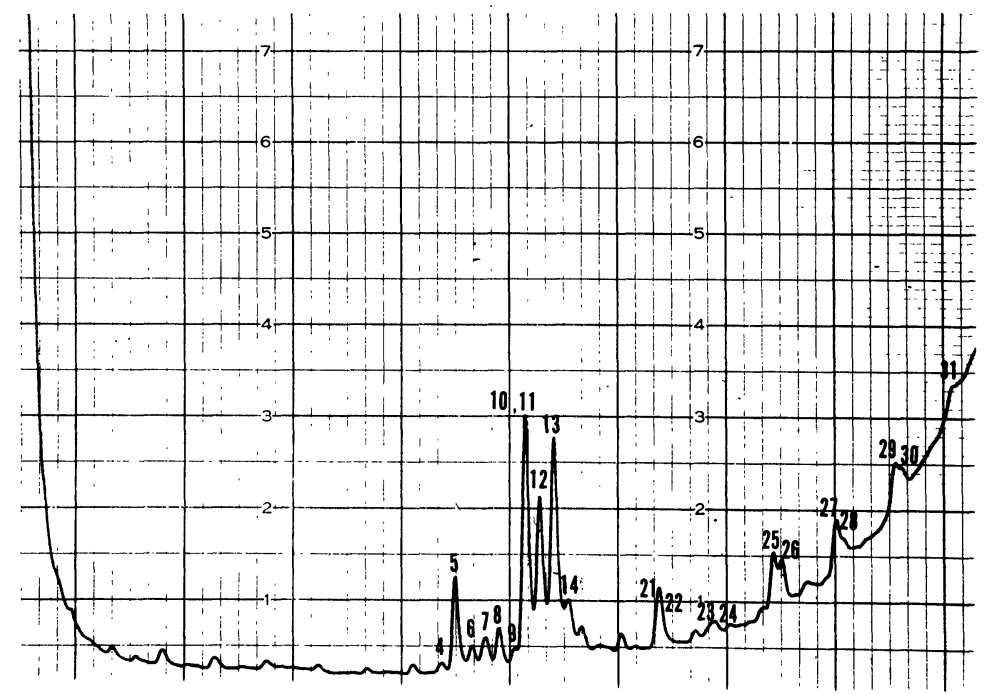

Fig. 2. GC trace of total cuticular hydrocarbons of Philotermes howardi. GC conditions same as for Fig. 1. 


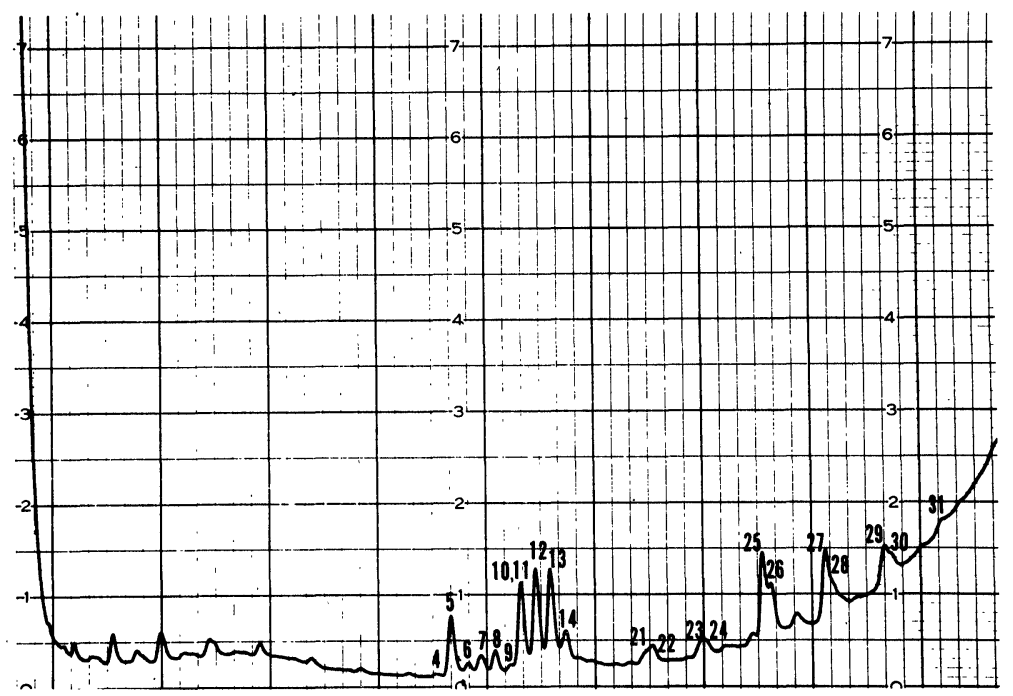

Fig. 3. GC trace of total cuticular hydrocarbons of Trichopsenius depressus. GC conditions same as for Fig. 1.

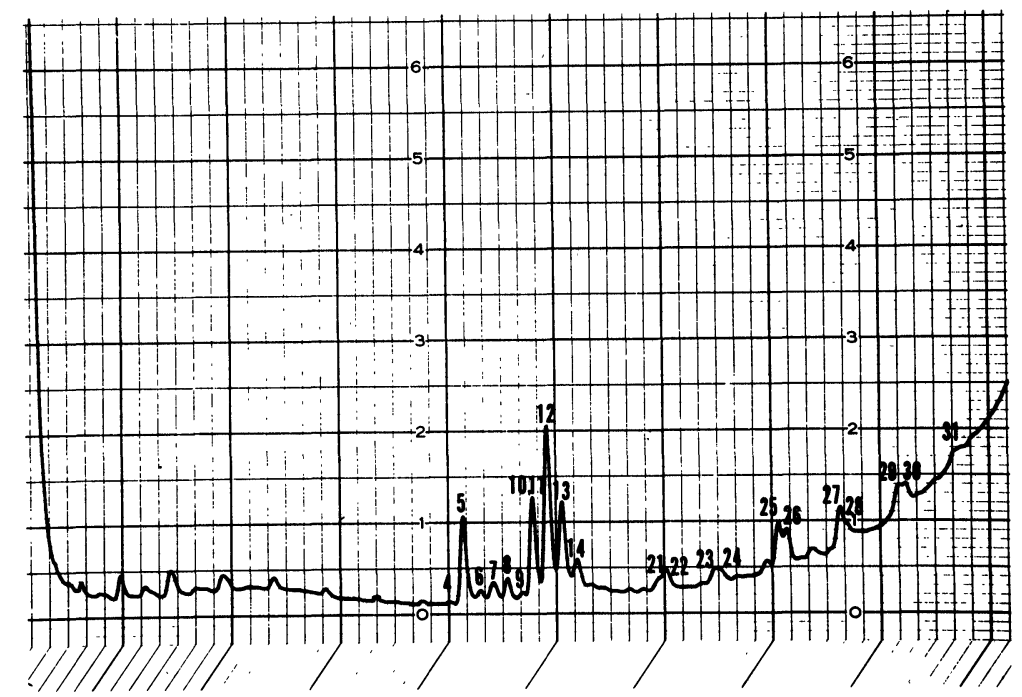

Fig. 4 GC trace of total cuticular hydrocarbons of Xenistusa hexagonalis. GC conditions same as for Fig. 1. 
termite host is strongly suggestive for their role as integrating factors. It also supports our earlier hypothesis that cuticular hydrocarbons may serve as species recognition cues (Howard et al., 1978; Blomquist et al., 1979; Howard et al., 1980a; Howard et al., 1982). Behavioral evidence for this interpretation comes from the finding (Howard, unpublished observations) that live $T$. depressus placed into laboratory colonies of $R$. flavipes were killed by the termites within a 24-hour period (five observations). Similarly, the placing of live $T$. frost $i$ into laboratory colonies of $R$. virginicus results in their being killed (five observations). Beetles can be freely exchanged among different colonies of their hosts however. These two Trichopsenius spp. are nearly identical morphologically and behaviorally, but differ markedly with respect to cuticular hydrocarbons. Similar transplants of workers or soldiers of $R$. flavipes or $R$. virginicus into colonies of the other species also resulted in the death of the alien individual (five observations). Transplants of conspecific termites into different colonies did not produce agonistic interactions (five observations). As with the beetles, the two termite species are morphologically and behaviorally quite similar. We have shown that $R$. virginicus workers are antagonistic towards neutral, criticalpoint dried (CPD) conspecific workers treated with $R$. flavipes cuticular hydrocarbons (Howard et al., 1982), but are not aggressive toward CPD workers treated with $R$. virginicus cuticular hydrocarbons. While we cannot exclude the possibility of other biochemical differences among either the beetles or their host termites, GC comparisons of total body extracts revealed none.

The termitophiles associated with $R$. virginicus (in common with other termitophiles) possess many epidermal glands (Kistner, 1979) which have often been postulated to be a source of chemicals which in some manner aids in the integration of the beetles into the termite society. While we cannot rule out this interpretation, we would like to suggest an alternative hypothesis for the function of these glandular products. Termitophiles are never found in great abundance (Wilson, 1971; Kistner, 1979), and the nature of termite nest-galley systems is such as to present substantial problems in the location and recognition of conspecifics. Perhaps these glands are producing pheromones directed at conspecifics rather than kairomones directed at their host. Since pheromones are usually produced in extremely 
small amounts, such an interpretation would explain the lack of GC evidence to date for beetle derived biochemicals different from those of their termite host. An experimental test of this hypothesis must await the development of suitable bioassays.

Reticulitermes virginicus and its termitophiles have been coevolving for a long period of time (Kistner, 1968, 1979). The beetles are totally integrated into the social life of the colony and appear to be chemically indistinguishable from the termites (chemical mimicry) vis-á-vis their cuticular hydrocarbons. Most known termitetermitophile associations, however, occur within the family Termitidae (Kistner, 1979). These associations are characterized by termitophiles ranging in status from nonintegrated to totally integrated. If our hypothesis is correct regarding the integrating role of cuticular hydrocarbons then a corresponding spectrum of congruences of hydrocarbon profiles would be predicted among the termitophiles of these communities. We are presently testing this hypothesis.

Many species of ants are known to have inquilines associated with them, but unlike termitophiles, these myrmecophiles are seldom host specific (Wilson, 1971). In addition, myrmecophiles seem to show a wider range of integration (or lack thereof) than do termitophiles. A correspondingly greater range of integrating mechanisms might therefore be expected, and have been found. These include body color, appeasement substances, trichomes, unicellular epidermal glands, physogastry, exudatoria and grandular antennae. All have been superbly reviewed by Wilson (1971) and Kistner (1979). The most recent addition to this plethora of mechanisms is the finding that the scarab beetle Myrmecaphodius excavaticollis (Blanchard) associated with various Solenopsis spp. ("fire ants") has a cuticular hydrocarbon composition which closely mimics that of its current ant host (Van der Meer, personal communication in Howard and Blomquist, 1982). The mechanism by which the beetles achieve this is unknown. Each of the four ant hosts that the scarab beetles is found with, however, has a unique hydrocarbon profile. Perhaps ants, like subterranean termites, also use cuticular hydrocarbons as species-recognition cues. Clearly a great deal remains to be learned before we achieve an adequate understanding of the diversity of relationships between social insects and their guests. 


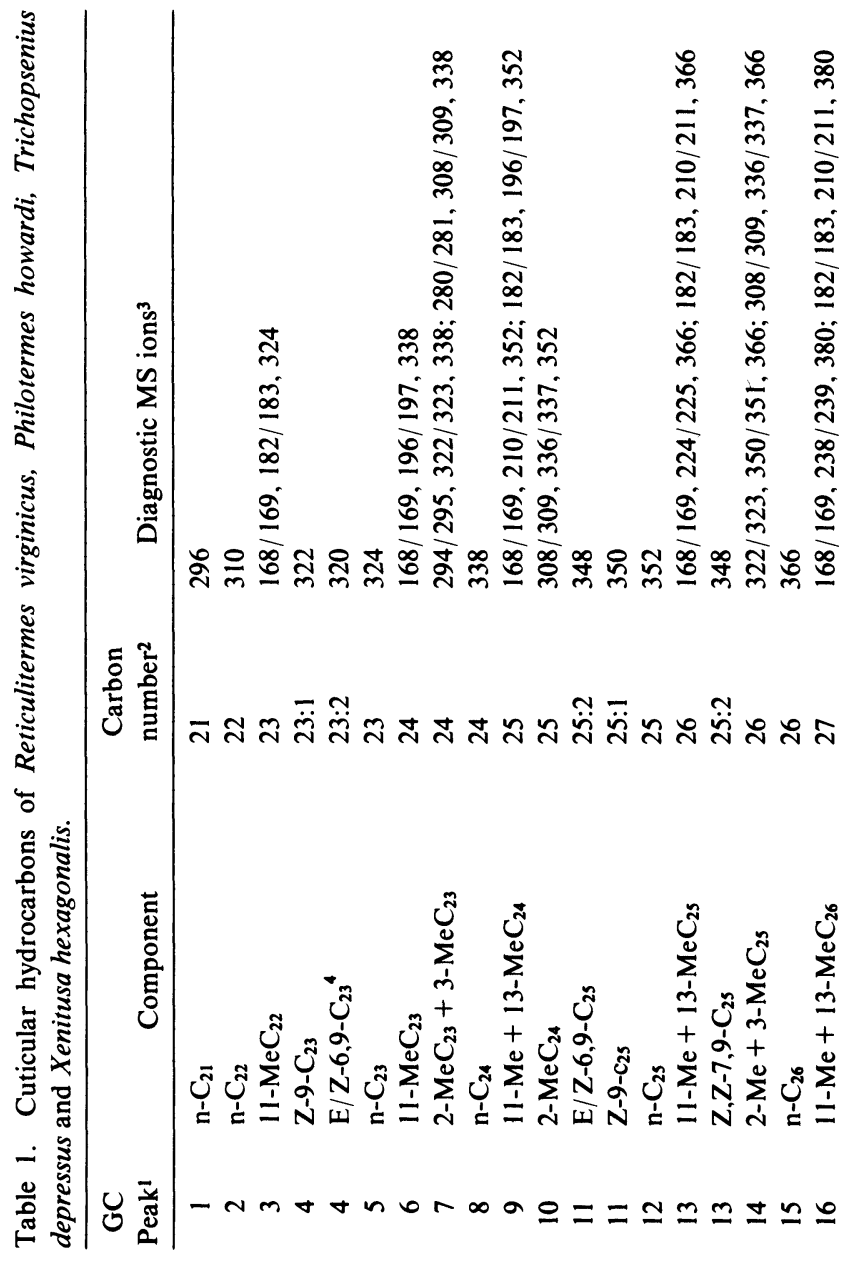




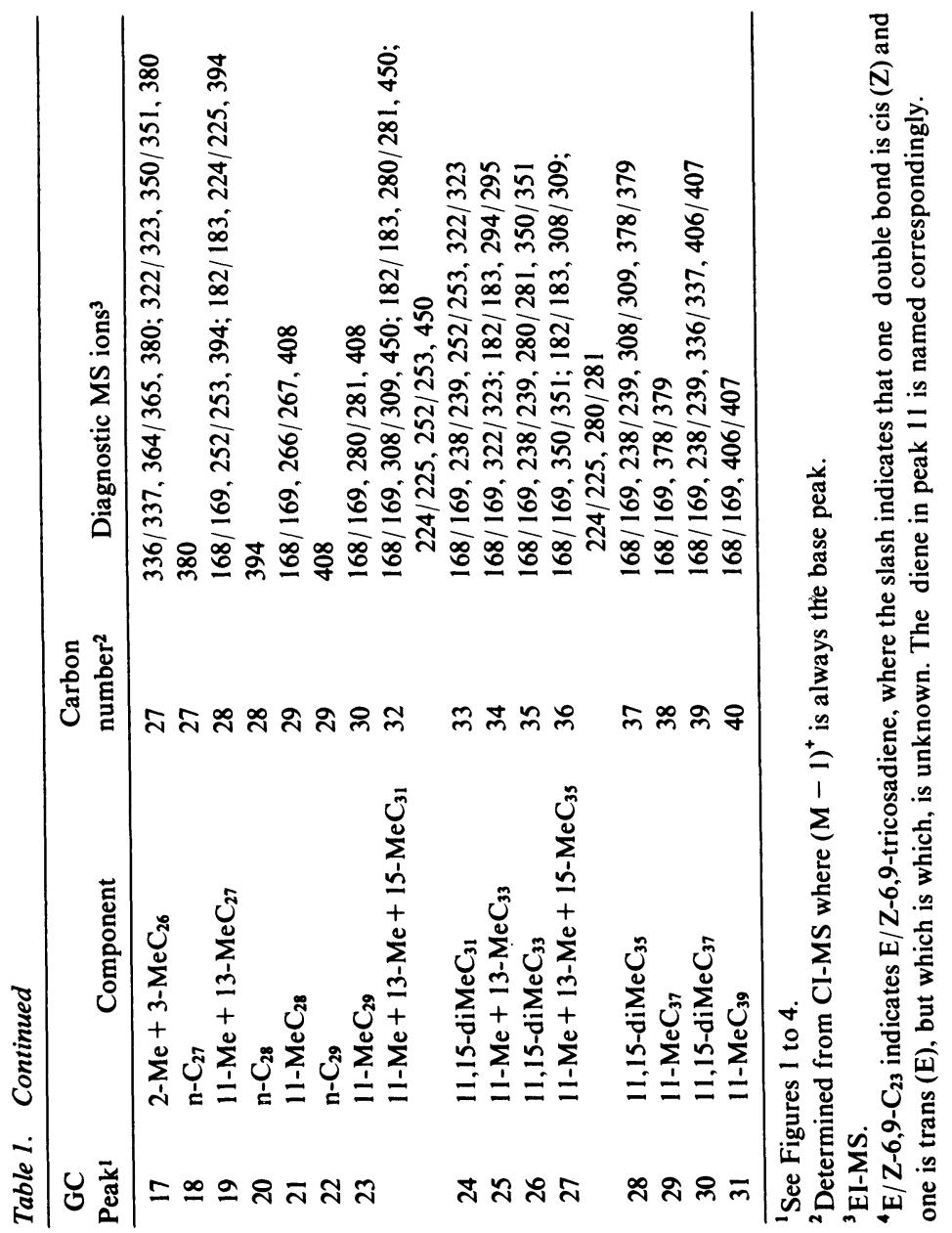




\section{SUMMARY}

The three highly integrated staphylinid termitophiles (Philotermes howardi Kistner and Gut, Trichopensius depressus Le Conte, and Xenistusa hexagonalis Seevers) associated with Reticulitermes virginicus (Banks), possess the same cuticular hydrocarbons as their host. This congruence is hypothesized to be a form of chemical mimicry and is postulated to function as a major way these beetles achieve integration into the termite society.

\section{ACKNOWLEDGEMENT}

G. J. Blomquist acknowledges the support of the Science and Education Administration of the U.S. Department of Agriculture under grant 7801064 from the Competitive Research Grant Office.

\section{Literature Cited}

Blomquist, G. J., R. W. Howard, and C. A. McDaniel.

1979. Structures of the cuticular hydrocarbons of the termite Zootermopsis angusticollis (Hagen). Insect. Biochem. 9: 365-370.

Blomquist, G. J., R. W. Howard, C. A. McDaniel, S. Remaley, L. A. Dwyer, AND D. R. NeLSON.

1980. Application of methoxymercuration-demercuration followed by mass spectrometry as a convenient microanalytical technique for double-bond location in insect-derived alkenes. J. Chem. Ecol. 6(1): 257-269.

HOWARD, R. W.

1978. Proctodeal feeding by termitophilous Staphylinidae associated with $R e$ ticulitermes virginicus (Banks). Science 201: 541-543.

HoWARD, R. W., AND G. J. BLomQuist.

1982. Chemical ecology and biochemistry of insect hydrocarbons. Annu. Rev. Entomol. 27: 149-172.

Howard, R. W., C. A. MCDaniel, and G. J. BlomQuist.

1978. Cuticular hydrocarbons of the eastern subterranean termite, Reticulitermes flavipes (Kollar) (Isoptera: Rhinotermitidae). J. Chem. Ecol. 4(2): 233-245.

Howard, R. W., C. A. MCDaniel, and G. J. Blomquist.

1980a. Chemical mimicry as an integrating mechanism: cuticular hydrocarbons of a termitophile and its host. Science 210: 431-433.

Howard, R. W., C. A. McDaniel, D. R. Nelson, and G. J. Blomquist.

1980b. Chemical ionization mass spectrometry: application to insect-derived cuticular alkanes. J. Chem. Ecol. 6(3): 609-623. 
Howard, R. W., C. A. McDaniel, D. R. Nelson, G. J. Blomquist, L. T. Gelbaum AND L. H. ZALKOW.

1982. Cuticular hydrocarbons of Reticulitermes virginicus (Banks) ${ }^{1}$ and their role as potential species- and caste-recognition cues. J. Chem. Ecol. 8: 1227-1239.

JACKSON, L. L., AND G. J. BLOMQUist.

1976. Insect waxes. P. 201-233. In Chemistry and Biochemistry of Natural Waxes. P. E. Kolattukudy (ed.). Elsevier, Amsterdam, Oxford, and New York. 459 p.

KATES, M.

1972. Techniques of Lipidology: Isolation, Analysis and Identification of Lipids. North-Holland Publishing Company, Amsterdam, and American Elsevier Publishing Company, New York. 610 p.

KISTNER, D. H.

1968. Revision of the African species of the termitophilous tribe Corotocini (Coleoptera: Staphylinidae). I. A new genus and species from Ovamboland and its zoogeographic significance. J. N. Y. Entomol. Soc. 76: 213-221.

KISTNER, D. H.

1979. Social and evolutionary significance of social insect symbionts. P. 339-413. In Social Insects. Vol. 1. H. R. Hermann (ed.). Academic Press, New York, San Francisco, and London. 437 p.

WILSON, E. O.

1971. The Insect Societies. The Belknap Press of Harvard University Press, Cambridge, Mass. 548 p. 

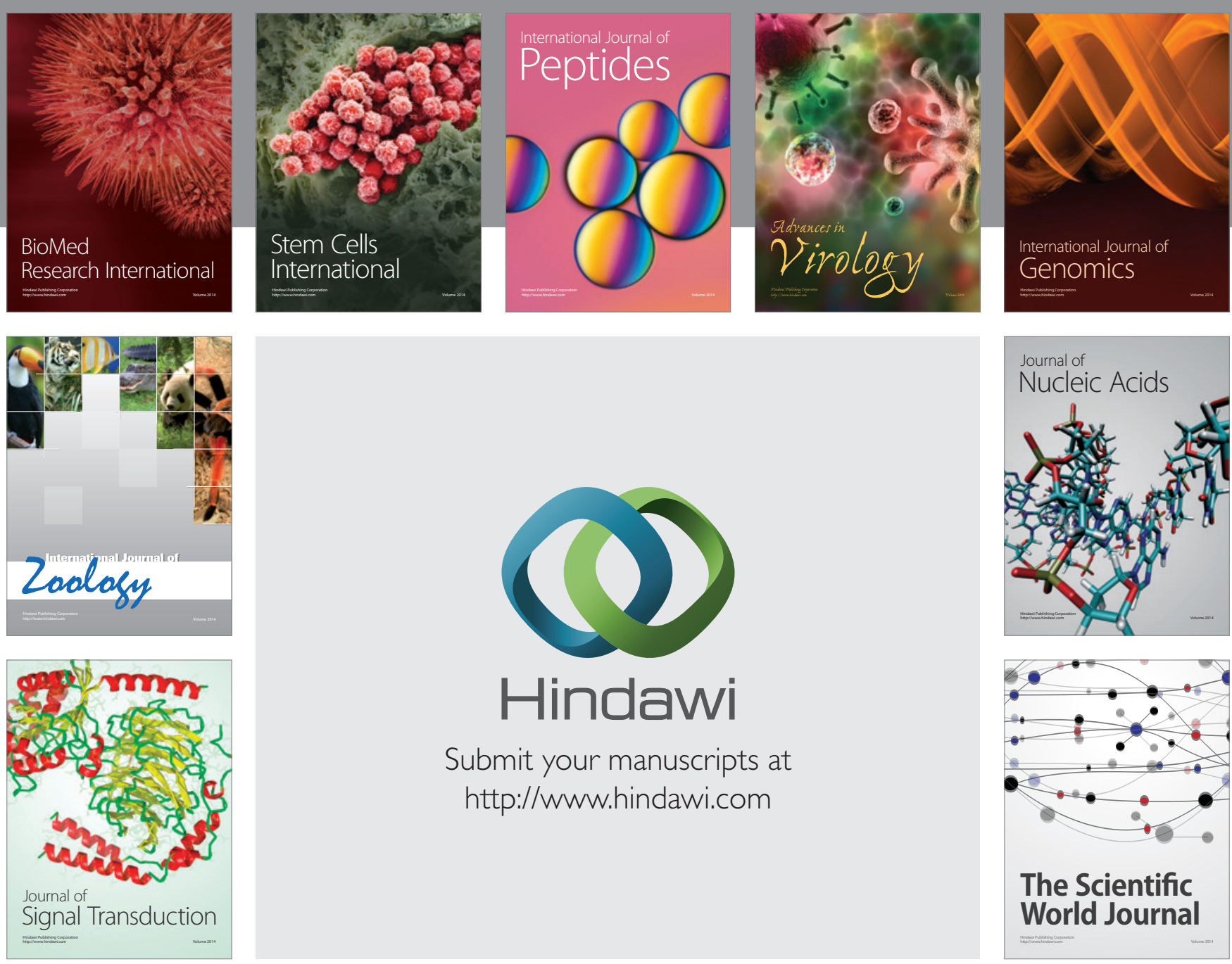

Submit your manuscripts at

http://www.hindawi.com
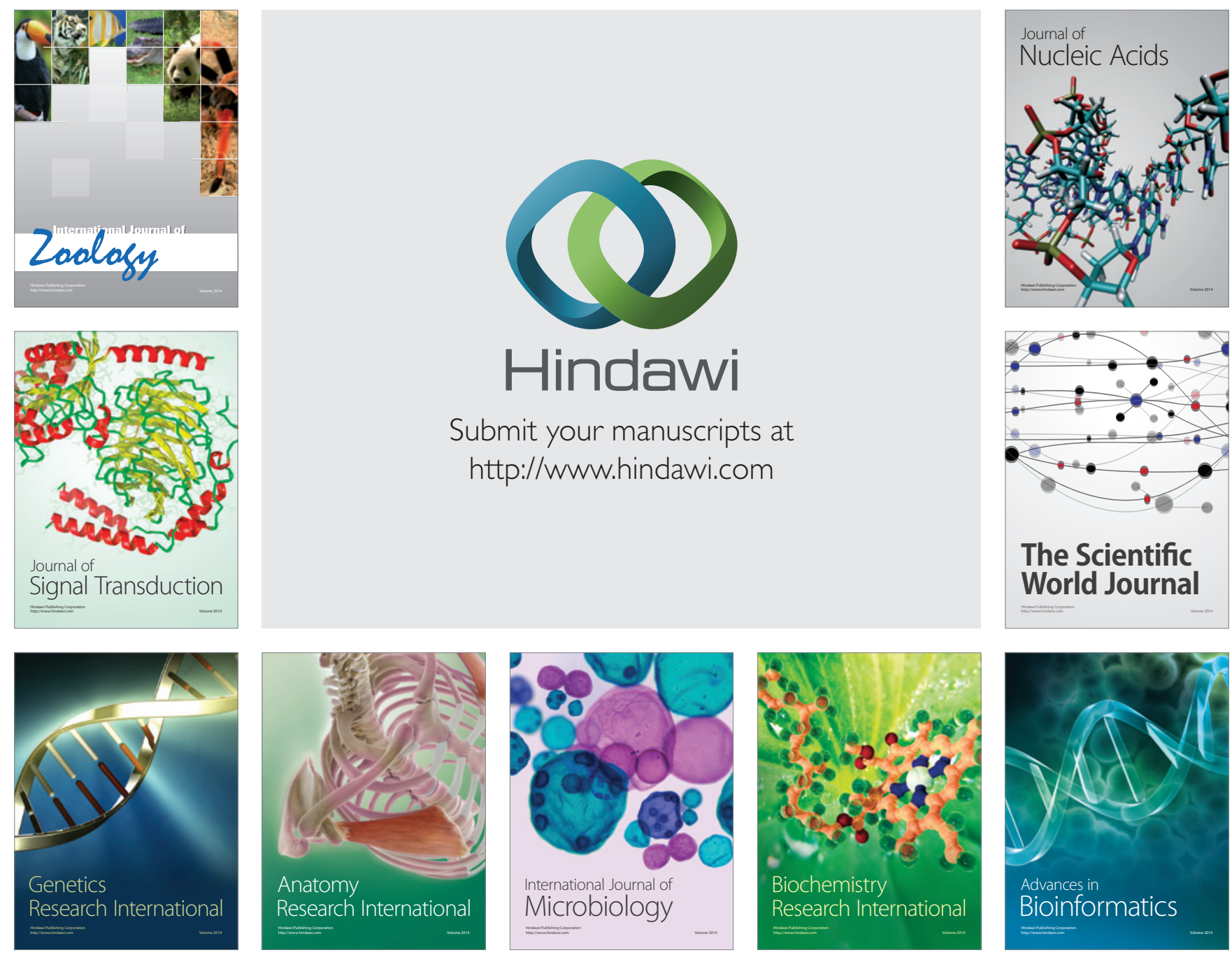

The Scientific World Journal
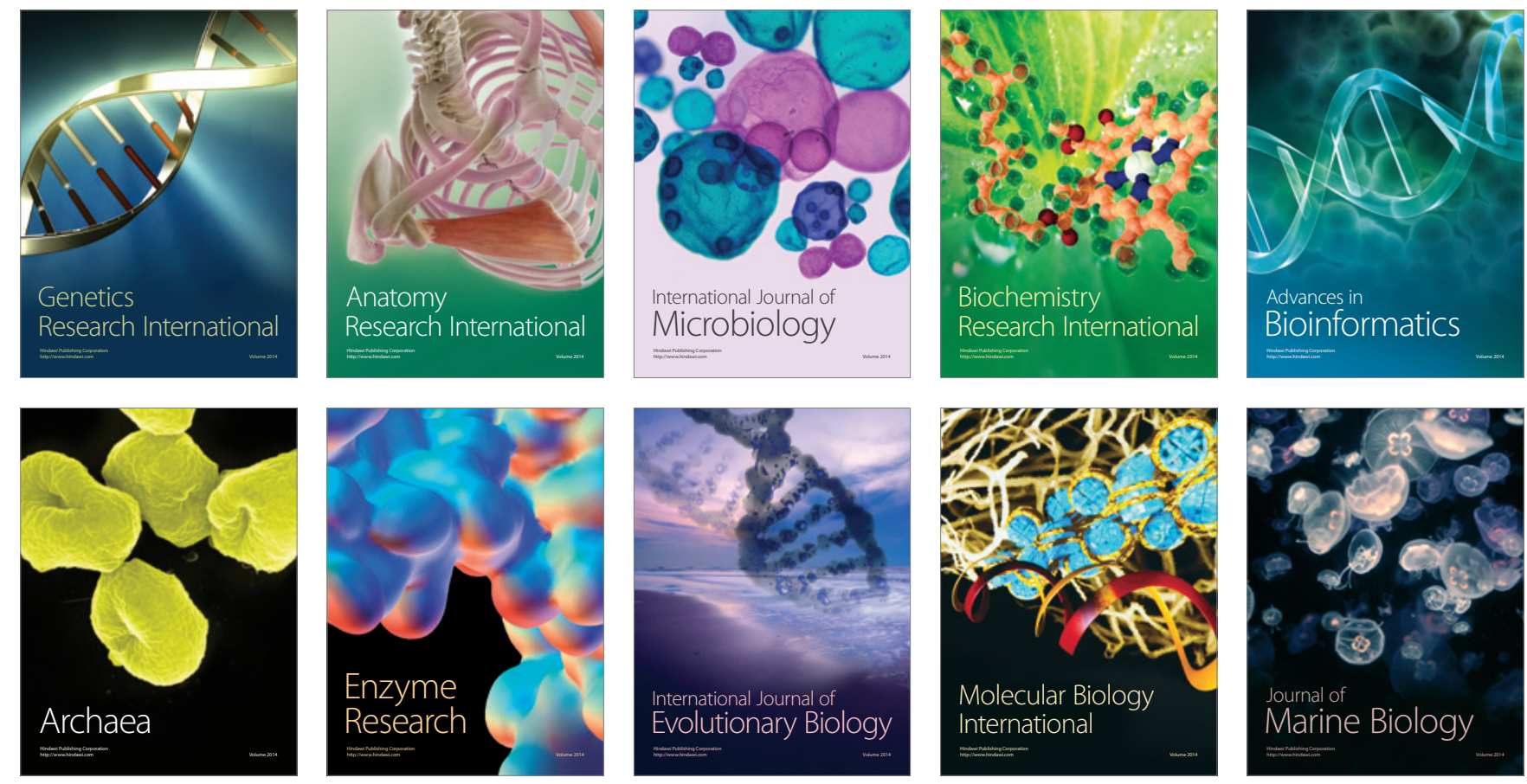